\title{
Dynamic lot sizing with multiple suppliers, backlogging and quantity discounts
}

\author{
Mehdi Ghaniabadi ${ }^{\mathrm{a}, *}$, Amin Mazinani ${ }^{\mathrm{b}}$ \\ a Department of Industrial Engineering, Bilkent University, Ankara, Turkey \\ ${ }^{\mathrm{b}}$ Department of Computer Engineering and Information Technology, Amirkabir University of Technology, Tehran, Iran
}

\section{A R T I C L E I N F O}

\section{Article history:}

Received 5 June 2016

Received in revised form 12 May 2017

Accepted 26 May 2017

Available online 29 May 2017

\section{Keywords:}

Dynamic lot sizing

Supplier selection

Quantity discounts

Backlogging

Inventory control

\begin{abstract}
A B S T R A C T
This paper studies the dynamic lot sizing problem with supplier selection, backlogging and quantity discounts. Two known discount types are considered separately, incremental and all-units quantity discounts. Mixed integer linear programming (MILP) formulations are presented for each case and solved using a commercial optimization software. In order to timely solve the problem, a recursive formulation and its efficient implementation are introduced for each case which result in an optimal and a near optimal solution for incremental and all-units quantity discount cases, respectively. Finally, the execution times of the MILP models and forward dynamic programming models obtained from the recursive formulations are presented and compared. The results demonstrate the efficiency of the dynamic programming models, as they can solve even large-sized instances quite timely.
\end{abstract}

(c) 2017 Elsevier Ltd. All rights reserved.

\section{Introduction}

In recent global business environment, pressure from competitive markets have forced manufacturers to reduce their operational costs. Many firms deal with different suppliers for procuring their requirements where each supplier reduces the price of a product for the larger purchased amounts. There exist two known discount schemes in the literature. First, the incremental discount scheme, which refers to a situation in which the unit price of a particular discount level is applied just to the amount corresponding to that level. Second, the all-units quantity discount scheme under which a discounted unit price is charged for all purchased amount.

At the same time, inventory holding and backlogging costs are incurred for storing the procured products and not fulfilling the product needs when required, respectively. Therefore, finding the optimal set of suppliers and the quantity of the item to be procured in each period of time, considerably reduces the inventory and supplier related costs of the firm. In this paper, we introduce new and efficient mathematical procedures to manage inventory and supplier selection. Simultaneously, we find the best combination of suppliers and amounts to be purchased over a planning horizon with the goal of minimizing the total inventory and purchase costs.

In the literature of inventory management, dynamic lot sizing problem has received considerable attention especially when a

\footnotetext{
* Corresponding author.

E-mail address: mehdi.ghaniabadi@gmail.com (M. Ghaniabadi).
}

set of planning periods is taken into account. In a seminal paper, Wagner and Whitin (1958) proposed a forward dynamic programming algorithm to solve the dynamic lot sizing problem (DLSP) for a single item and a single supplier. As Wagner and Whitin's (1958) algorithm was too complex to be implemented, Evans (1985), Federgruen and Tzur (1991), Wagelmans, Van Hoesel, and Kolen (1992), Aggarwal and Park (1993), and Van Hoesel, Kuik, Salomon, and Van Wassenhove (1994) proposed other algorithms to enhance its empirical efficiency. Zangwill (1969), Song and Chan (2005), Absi, Kedad-Sidhoum, and Dauzère-Pérès (2011) and Chu, Chu, Zhong, and Yang (2013) studied the DLSP with allowing backlog. In addition, some studies were done in the area of the DLSP extended to quantity discount case in which the unit price varied in diverse amounts of a purchased item. In this field, Callerman and Whybark (1977) and Chung, Chiang, and Lu (1987) introduced a mixed integer programming model and a dynamic programming model, respectively, to obtain the optimal solution. Fordyce and Webster (1985) modified the Wagner and Whitin's (1958) algorithm to a tabular procedure to solve the DLSP with quantity discount. However, Sumichrast (1986) showed that their algorithm did not give the optimal solution necessarily. Federgruen and Lee (1990), introduced algorithms for both incremental and all-units quantity discount cases. Later, Xu and Lu (1998) demonstrated that Federgruen and Lee's (1990) solution for all-units quantity discount case did not give the optimal policy in some special instances; then they presented an optimal method by modifying Federgruen and Lee's (1990) algorithm. Chyr, Huang, and Lai (1999) proposed an 
optimal recursive relationship for the DLSP with all-units quantity discount. Hu and Munson (2002) examined different solution methods regarding the DLSP with incremental quantity discount. Lee, Kang, and Lai (2013) introduced a mixed integer programming model and a genetic algorithm to solve the DLSP with transportation cost and all-units quantity discount. None of the mentioned authors considered the DLSP with quantity discounts and backlogging together, for a single supplier.

Some authors studied the extension of the single item DLSP to the multi-supplier case without quantity discounts consideration (Jaruphongsa, Cetinkaya, \& Lee, 2005; Zhao \& Klabjan, 2012). In this case, the buyer needs to determine the amount to be purchased in each period and from which suppliers (supplier selection).

With quantity discounts and non-backlog consideration, Tempelmeier (2002) proposed a new mathematical model and a heuristic to solve the problem. Bai and Xu (2011) considered three different cost structures consisting incremental and all-units quantity discounts and multiple set-ups cost, and presented the optimal solutions. Lee, Kang, Lai, and Hong (2013) proposed a mixed integer programming and an efficient genetic algorithm for solving the problem. None of the mentioned papers considered the backlogging cost along with quantity discount. However, Kang and Lee (2013) supposed the problem with stochastic demands, shortage cost and the objective of minimizing the total cost and maximizing service level. Then, they derived a multi-objective programming model, a mixed integer programming model and a heuristic dynamic programming as a solution methodology. Parsa, Khiav, Mazdeh, and Mehrani (2013) considered the problem of lot sizing for the case of a single item along with supplier selection in a two-stage supply chain. The suppliers could also offer either all-unit or incremental discount schemes and a dynamic programming methodology is provided to solve the proposed model. In a similar study, Mazdeh, Emadikhiav, and Parsa (2015) investigated single-item dynamic lot sizing problem with supplier selection under incremental and all-unit quantity discounts. Due to problem complexity, a new heuristic was developed to solve the problem.

Roodhooft and Konings (1996), Rosenblatt, Herer, and Hefter (1998), Dai and Qi (2007), discussed other forms of the single item supplier selection problem without considering the DLSP and quantity discounts. With the assumption of quantity discounts' availability, Chaudhry, Forst, and Zydiak (1993) considered incremental and all-units quantity discounts, quality and capacity limitations and proposed a mixed integer linear programming approach to minimize the procuring costs over a single period. Chang (2006) brought up the problem studied by Rosenblatt et al. (1998) in the field of economic order quantity with multiple capacitated suppliers, and proposed an exact approach that also held for all-units quantity discount case. Chang, Chin, and Lin (2006) introduced a mixed integer method to determine the economic order quantity where assumed some other real-world conditions in the problem like resource limitations and variable lead-time. Burke, Erenguc, and Vakharia (2008) proposed a branch and bound algorithm to find the optimal quantity to be purchased from a set of capacitated suppliers offering incremental quantity discount.

This paper considers the DLSP with multiple suppliers backlogging, and incremental and all-units quantity discounts. The most related articles to the current paper are the ones by Fordyce and Webster (1985), Federgruen and Lee (1990), Chyr et al. (1999) and $\mathrm{Hu}$ and Munson (2002), for the single supplier case, and Tempelmeier (2002), Bai and Xu (2011), Lee, Kang, Lai, and Hong (2013) and Mazdeh et al. (2015), for the multiple supplier case.

Therefore, realizing that the existing models in the literature do not develop a deterministic model when backlogging, quantity discounts and single or multiple suppliers are considered at same time, we propose two new models by combining them. To our knowledge, there exists no study in the DLSP literature to consider backlogging and quantity discounts together where the demand is deterministic. In summary, we make the following contributions in this paper: we study an extension of DLSP by backlogging, multiple suppliers and quantity discounts consideration. We establish new mixed integer linear programming models for both incremental and all-units quantity discount cases which are solved optimally using a commercial optimization software. For each case, a recursive formulation and its efficient implementation are also developed yielding an optimal solution for incremental discount case, and a near optimal solution for all-units discount case. We perform the corresponding numerical studies which suggest that for incremental discount case, the dynamic programming model obtained from the efficient implementation of the recursive formulation provides the best performance, as it can timely and optimally solve even large sized instances. For all-units discount case, MILP model can only solve small sized instances optimally in a reasonable time whereas the dynamic programming model obtained from the efficient implementation of the recursive formulation reaches a near optimal solution quite timely even for large sized instances.

The rest of the article is organized as follows: in Section 2, the problem description and notations are presented. In Section 3, we establish the new mixed integer linear programming models and the recursive formulations to solve the problem for both incremental and all-units quantity discount cases. Numerical examples, computational results and conclusions are stated in Sections 4,5 and 6 , respectively.

\section{Problem explanation}

Consider a buyer procuring his known demands over multiple periods from a variety of qualified suppliers. Each supplier presents different quantity discount levels for each period and charges the buyer with lower unit prices for greater purchased quantities of each order. In this study, two discount schemes are considered; incremental and all-units quantity discounts.

Furthermore, the buyer pays unit holding costs if the demand of a period is procured in earlier periods. Unit backlogging costs are incurred when the demand of a period is not satisfied on time. There is also a fixed ordering cost for each periodic order from each supplier. The objective is to find an ordering plan that minimizes the total costs over the planning periods.

The dynamic lot sizing problem (DLSP), refers to minimizing the total inventory holding costs and fixed ordering costs over multiple planning periods where there is only one supplier. Therefore, the problem discussed in this paper is the extension of the DLSP to the backlogging, quantity discounts and supplier selection.

In this paper, the dynamic lot sizing problem (DLSP) with multiple suppliers, incremental discount and backlogging is considered by P1, and the DLSP with multiple suppliers, all-units discount and backlogging by $\mathrm{P} 2$.

In order to depict the mathematical models and formulations of this article, the following notations are considered:

Indices:

- $s$ index of suppliers $(s=1, \ldots, S)$.

- $t$ index of time periods $(t=1, \ldots, T)$.

- $l$ index of discount levels $(l=1, \ldots, L)$.

\section{Parameters:}

- $d_{t}$ demand of the item in period $t$.

- $Q_{\text {Ist }}$ the upper bound quantity of discount level $l$ for supplier $s$ in period $t$, where $Q_{0 s t}=0$. 
- $U_{\text {lst }}$ unit item price of discount level $l$ for supplier $s$ in period $t$ where the inequalities $Q_{(l-1) s t}<\sum_{k=1}^{l} X_{k s t} \leqslant Q_{l s t}$ and $Q_{(I-1) s t}<X_{l s t} \leqslant Q_{l s t}$ hold for incremental and all-units quantity discount cases, respectively.

- $h_{t}^{+}$unit holding cost in period $t$.

- $h_{t}^{-}$unit backlogging cost in period $t$.

- $C_{s t}$ fixed ordering cost of supplier $s$ in period $t$.

Decision variables:

- $X_{\text {lst }}$ amount of the item procured in discount level $l$ from supplier $s$ in period $t$ (Note that when the supplier offers incremental quantity discounts, $X_{\text {lst }}$ can take any value between 0 and $Q_{l s t}-Q_{(l-1) s t}$. Whereas, when the supplier offers all-units quantity discounts, $X_{l s t}$ can take any value between 0 and $\left.Q_{l s t}\right)$.

- $G_{t}$ total amount of the item procured in period $t$ in the presence of only one supplier.

- $G_{s t}$ total amount of the item procured from supplier $s$ in period $t$.

- $Y_{\text {lst }} 1$ if the buyer purchases in discount level $l$ from supplier $s$ in period $t, 0$ otherwise.

- $R_{s t} 1$ if the buyer purchases from supplier $s$ in period $t, 0$ otherwise.

- $I_{t}^{+}$on hand inventory quantity at the end of period $t$, where $I_{0}^{+}=I_{T}^{+}=0$.

- $I_{t}^{-}$backlog inventory quantity at the end of period $t$, where $I_{0}^{-}=I_{T}^{-}=0$.

In our settings, ordering and unit inventory costs can vary with time period. The first reason is to be consistent with many relevant papers which have considered the same assumption regarding ordering cost (Absi et al., 2011; Bai \& Xu, 2011; Chu et al., 2013; Chyr et al., 1999; Mazdeh et al., 2015; Tempelmeier, 2002; Wagner \& Whitin, 1958; Zangwill, 1969), unit holding cost (Absi et al., 2011; Bai \& Xu, 2011; Chu et al., 2013; Chyr et al., 1999; Mazdeh et al., 2015; Wagner \& Whitin, 1958; Zangwill, 1969), and unit backlog cost (Absi et al., 2011; Chu et al., 2013; Zangwill, 1969). Second, in some real world situations these costs may vary. For instance, the holding costs may increase due to a rise in the costs related to air-conditioning. The buyer may priorities some of his customers, which may make a purchase during specified periods. Due to the importance of these customers for the buyer, the unit backlog cost of the corresponding periods may be higher than the other periods. Shipping costs can be affected by seasonality, especially if it is done by a third-party, which impacts the ordering costs (in case shipping costs are assumed to be fixed). Moreover, in countries with a high inflation rate, all these costs may increase throughout the year.

\section{Solution procedures}

\subsection{Optimal solutions for P1}

In this section, the optimal solutions of dynamic lot sizing problem with multiple suppliers, backlogging and incremental quantity discount, including a mixed integer linear programming model (MILP), a recursive formulation and its efficient implementation, are discussed.

The MILP formulation of the problem for P1 is as follows.

$\min z=\sum_{t=1}^{T} \sum_{s=1}^{S} C_{s t} R_{s t}+\sum_{t=1}^{T} \sum_{s=1}^{S} \sum_{l=1}^{L} U_{l s t} X_{l s t}+\sum_{t=1}^{T} h_{t}^{+} I_{t}^{+}+\sum_{t=1}^{T} h_{t}^{-} I_{t}^{-}$

subject to:

$I_{t}^{+}-I_{t}^{-}=I_{t-1}^{+}-I_{t-1}^{-}+\sum_{s=1}^{S} \sum_{l=1}^{L} X_{l s t}-d_{t} \quad \forall t$
$\sum_{l=1}^{L} X_{l s t} \leqslant R_{s t} M \quad \forall s, t$

$\left(Q_{l s t}-Q_{(l-1) s t}\right) Y_{l s t} \leqslant X_{l s t} \leqslant\left(Q_{l s t}-Q_{(l-1) s t}\right) Y_{(l-1) s t} \quad \forall l, s, t$

$Y_{\text {lst }}=0,1 \quad \forall l, s, t$

$R_{s t}=0,1 \quad \forall s, t$

In the above MILP model, the objective function minimizes the total cost which consists of ordering costs, the unit purchase costs, holding costs and backlogging costs. The first constraint shows the relation between on hand and backlog inventory quantities in a period and other parameters and variables. The second constraint ensures that if a purchase is occurred in period $t$ from supplier $s$, then $R_{s t}$ is set to 1 and the corresponding ordering $\operatorname{cost} C_{s t}$ is added up to the total cost which is represented by the objective function. Here, $M$ is a sufficiently large number which can be equal or greater than $\sum_{k=1}^{T} d_{k}$. The third constraint of the first MILP model, sets the procured amount between the lower and upper bounds of a supplier's discount level $l$ according to incremental quantity discount policy of each supplier for each period.

In order to define the properties of the optimal solution for P1, consider the following theorem.

Theorem 1. In the presence of only one supplier, there exists an optimal solution where for each period t at most one of the quantities $I_{t-1}^{+}, I_{t}^{-}, G_{t}$ is nonzero.

Proof. Zangwill (1969) introduced this property of optimality for dynamic lot sizing problem with backlogging and concave costs, by deriving from similar findings of a more general model presented by Zangwill (1966). As all of the cost structures including holding, backlogging, ordering and purchase costs remain concave in incremental discount case, so this theorem also holds for P1. Concavity of the sum of fixed ordering and the purchase costs for incremental discount case can be shown through the Fig. 2 presented in the paper of Stadtler (2007) for a single item and one supplier. Besides, clearly both of the holding and backlogging cost functions $\left(h_{t}^{+} I_{t}^{+}, h_{t}^{-} I_{t}^{-}\right)$are concave as they are affine. $\square$

It follows from Theorem 1 that in each purchasing period, the procured amount satisfies exact requirements. In addition, Theorem 1 implies that the whole demands between two consecutive regeneration periods, must be satisfied by purchasing in just one period between those regeneration periods. Regeneration period refers to each period $t$ where $I_{t}^{+}=I_{t}^{-}=0$.

In order to achieve the optimal policy for the multiple supplier case, first the following lemma is considered.

Lemma 1. If purchasing occurs in a period, in the optimal solution, the buyer procures only from one supplier.

Proof. The proof is similar to that of non-backlogging case with incremental quantity discount by Bai and Xu (2011).

Using Lemma 1, it can be stated that Theorem 1 also holds for multiple supplier case and it contributes to the existence of an optimal solution where for each period $t$ at most one of the quantities $I_{t-1}^{+}, I_{t}^{-}, G_{s t}$ is nonzero. Consequently, the implications of Theorem 1 will hold for solving P1. Using Theorem 1 and its implications, the following recursive relation can be obtained in order to solve P1.

$F_{n}=\min _{\substack{1 \leqslant s \leqslant s \\ 0 \leqslant m \leqslant n-1 \\ m+1 \leqslant j \leqslant n \leqslant T}}\left[F_{m}+D_{m n j s}\right]$ 
In the above equation, $F_{0}=0$ and $F_{m}$ indicates the total cost of optimal plan from period 0 to period $m$. $D_{m n j s}$ is the total cost of a plan where the whole demands of periods $m+1$ to $n$ is procured in period $j$ from supplier $s$, while $m$ and $n$ are two consecutive regeneration periods and $I_{m}^{+}=I_{m}^{-}=I_{n}^{+}=I_{n}^{-}=0$. Thus, $D_{m n j s}$ can be stated for P1 as Eq. (8). period $j$ from supplier $s$ while $Q_{(l-1) s j}<\sum_{t=m+1}^{n} d_{t} \leqslant Q_{I s j}$; and $P_{m n j s}$ states the corresponding total of ordering and inventory costs. $B_{j t}$ is equal to unit holding costs of period $t$ and $E_{j t s}$ denotes the ordering or inventory costs of period $t$, when the buyer purchases from supplier s in period $j$.

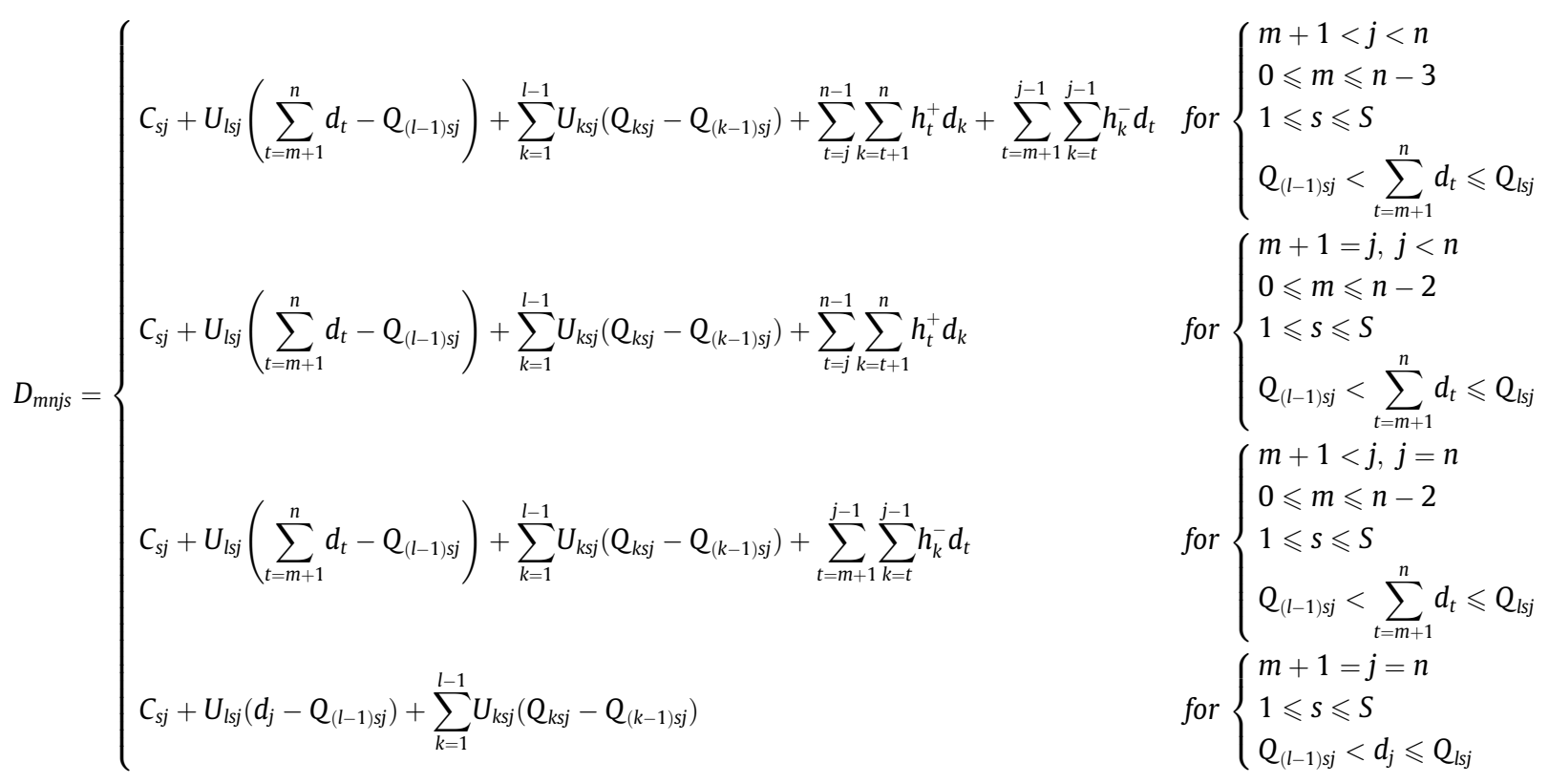

Evans (1985) implemented the Wagner and Whitin's (1958) recursive solution in an efficient way to solve the non-backlog dynamic lot sizing problem (DLSP) without quantity discounts. He used the old calculations to obtain the new ones, in order to reduce the computational efforts. Using the same idea, $D_{m n j s}$ can be implemented in an efficient manner, as Eq. (9).

$D_{\text {mnjs }}=P_{m n j s}+U_{l s j}\left(\sum_{t=m+1}^{n} d_{t}-Q_{l s j}\right)+\sum_{k=1}^{l-1} U_{k s j}\left(Q_{k s j}-Q_{(k-1) s j}\right)$

where

$P_{m n j s}= \begin{cases}E_{n n s} & \text { if } m+1=n=j \\ P_{(m+1) n n s}+E_{n(m+1) s} & \text { if } n=j, m+1<n \\ P_{m(n-1) j s}+E_{j n s} & \text { if } m+1 \leqslant j<n\end{cases}$

$E_{j t s}= \begin{cases}C_{t s} & \text { if } t=j \\ B_{j t} d_{t} & \text { otherwise }\end{cases}$

$B_{j t}= \begin{cases}B_{j(t+1)}+h_{t}^{-} & \text {if } t<j \\ 0 & \text { if } t=j \\ B_{j(t-1)}+h_{t-1}^{+} & \text {if } t>j\end{cases}$

$P_{m n j s}$ can also be stated as follows.

$P_{m n j s}= \begin{cases}E_{n n s} & \text { if } m+1=n=j \\ P_{m(n-1)(m+1) s}+E_{(m+1) n s} & \text { if } m+1=j, n>j \\ P_{(m+1) n j s}+E_{j(m+1) s} & \text { if } m+1<j \leqslant n\end{cases}$

Eq. (9) is equivalent to Eq. (8) and demonstrates the total cost of a plan where the whole demands of periods $m+1$ to $n$ are procured in

\subsection{Optimal solution and heuristics for P2}

The MILP model of the problem for all-units quantity discount case is as below. This model can be solved optimally using the available commercial optimization softwares.

$\min z=\sum_{t=1}^{T} \sum_{s=1}^{S} C_{s t} R_{s t}+\sum_{t=1}^{T} \sum_{s=1}^{S} \sum_{l=1}^{L} U_{l s t} X_{l s t}+\sum_{t=1}^{T} h_{t}^{+} I_{t}^{+}+\sum_{t=1}^{T} h_{t}^{-} I_{t}^{-}$

subject to:

$I_{t}^{+}-I_{t}^{-}=I_{t-1}^{+}-I_{t-1}^{-}+\sum_{s=1}^{S} \sum_{l=1}^{L} X_{l s t}-d_{t} \quad \forall t$

$\sum_{l=1}^{L} X_{l s t} \leqslant R_{s t} M \quad \forall s, t$

$\sum_{l=1}^{L} Y_{l s t} \leqslant 1 \quad \forall s, t$

$X_{l s t}-Y_{l s t}\left(1+Q_{(l-1) s t}\right) \geqslant 0 \quad \forall l, s, t$

$X_{l s t}-Y_{l s t} Q_{l s t} \leqslant 0 \quad \forall l, s, t$

$Y_{l s t}=0,1 \quad \forall l, s, t$

$R_{s t}=0,1 \quad \forall s, t$

The descriptions of the objective function, and first and second constrains of the model, are similar to those of P1. The third, fourth and fifth constraints, set the procured amount between the lower and upper bounds of a supplier's discount level $l$ according to allunits quantity discount policy of each supplier for each period. 
Moreover, the solution procedures presented in Section 3.1 can be used to solve P2, using Eq. (22) instead of Eqs. (8), and (23) instead of Eq. (9). However, in this case, the optimal solution is not warranted, as the total purchase cost (fixed ordering plus the unit purchase costs) for $\mathrm{P} 2$ is not concave (see Fig. 1 presented in the paper of Stadtler (2007) for all-units discount, a single item and one supplier) and Theorem 1 only holds for concave cost structures.
Table 1

Data entry for the numerical example of P1.

\begin{tabular}{lllll}
\hline $\boldsymbol{t}$ & 1 & 2 & 3 & 4 \\
$\boldsymbol{d}_{\boldsymbol{t}}$ & 50 & 100 & 200 & 150 \\
$\boldsymbol{h}_{\boldsymbol{t}}^{+}$ & 3 & 1 & 2 & 1 \\
$\boldsymbol{h}_{\boldsymbol{t}}^{-}$ & 2 & 1 & 2 & 2 \\
$\boldsymbol{C}_{1 \boldsymbol{t}}$ & 350 & 300 & 600 & 500 \\
$\boldsymbol{C}_{2 \boldsymbol{t}}$ & 250 & 700 & 200 & 400 \\
\hline
\end{tabular}

$$
D_{m n j s}= \begin{cases}C_{s j}+U_{l s j} \sum_{t=m+1}^{n} d_{t}+\sum_{t=j}^{n-1} \sum_{k=t+1}^{n} h_{t}^{+} d_{k}+\sum_{t=m+1}^{j-1} \sum_{k=t}^{j-1} h_{k}^{-} d_{t} \text { for }\left\{\begin{array}{l}
m+1<j<n \\
0 \leqslant m \leqslant n-3 \\
1 \leqslant s \leqslant S \\
Q_{(l-1) s j}<\sum_{t=m+1}^{n} d_{t} \leqslant Q_{l s j}
\end{array}\right. \\
C_{s j}+U_{l s j} \sum_{t=m+1}^{n} d_{t}+\sum_{t=j}^{n-1} \sum_{k=t+1}^{n} h_{t}^{+} d_{k} \\
\text { for }\left\{\begin{array}{l}
m+1=j, j<n \\
0 \leqslant m \leqslant n-2 \\
1 \leqslant s \leqslant S \\
Q_{(l-1) s j}<\sum_{t=m+1} d_{t} \leqslant Q_{l s j}
\end{array}\right. \\
C_{s j}+U_{l s j} \sum_{t=m+1}^{n} d_{t}+\sum_{t=m+1}^{j-1} \sum_{k=t}^{j-1} h_{k}^{-} d_{t} \\
\text { for }\left\{\begin{array}{l}
m+1<j, j=n \\
0 \leqslant m \leqslant n-2 \\
1 \leqslant s \leqslant S \\
Q_{(l-1) s j}<\sum_{t=m+1}^{n} d_{t} \leqslant Q_{l s j}
\end{array}\right. \\
C_{s j}+U_{l s j} d_{j} \\
\text { for }\left\{\begin{array}{l}
m+1=j=n \\
1 \leqslant s \leqslant S \\
Q_{(l-1) s j}<d_{j} \leqslant Q_{l s j}
\end{array}\right.\end{cases}
$$

$$
D_{m n j s}=P_{m n j s}+U_{l s j} \sum_{t=m+1}^{n} d_{t}
$$

\section{Numerical examples}

In this part, we present numerical examples for both P1 and P2.

For P1, consider a buyer purchasing the requirements of a single product in four periods and from two suppliers which provide incremental quantity discounts. The following data is considered for this transaction (see Table 1).
According to Tables 4 and $5, F_{1}=850, F_{2}=2050, F_{3}=4150$ and $F_{4}=5700 . F_{4}=5700$ is the total cost of the optimal solution where the buyer purchases his whole demands from supplier 2 and in period 3.

For the all-units quantity discount case, i.e. P2, we consider a case-study presented by Kang and Lee (2013) where the demand is stochastic and the decision maker wants to minimize the total cost and maximize the service level in a multiple objective optimization problem. We use similar numerical data, however, we take into account the expected value of demands and a single objective of minimizing the total cost. This numerical example is described as follows.

Unit price offered by supplier $1= \begin{cases}11 & 0<\text { purchased quantity } \leqslant 200 \\ 9 & 200<\text { purchased quantity } \leqslant 400 \\ 8 & 400<\text { purchased quantity }\end{cases}$

Unit price offered by supplier $2= \begin{cases}12 & 0<\text { purchased quantity } \leqslant 150 \\ 10 & 150<\text { purchased quantity } \leqslant 350 \\ 8 & 350<\text { purchased quantity } \leqslant 450 \\ 7 & 450<\text { purchased quantity }\end{cases}$

Eqs. (7) and (8) are used to solve this example. The following Tables 2-5 demonstrate the values generated to reach the final solution.
A manufacturer in Taiwan assembles components of touch panels such as ITO glass and ITO film bought from Japan, and sells them to the customers through distribution channels. ITO film 
can become oxidized over time which incurs holding costs if an excessive amount is stored. Additionally, a shortage of ITO films causes stoppage in production flow of touch panels and postponement of meeting demands. Such situation entails backlogging costs. Table 6 below demonstrates demands of ITO films for 12 periods where each period corresponds to one day. The unit holding and backlog costs per period are $\$ 0.1$ and $\$ 20$, respectively.
The manufacturer currently purchases all of the requirements from one supplier, namely $\mathrm{A}$, and is also considering cooperation with suppliers B and C. Each supplier offers a specific all-units quantity discount scheme which is stated below. The ordering cost of suppliers A, B and C are $\$ 230, \$ 200$ and $\$ 150$, respectively.

The manufacturer wants to decide what quantities, from which suppliers and in which periods to purchase in order to meet

Unit price offered by supplier $A= \begin{cases}\$ 3.00 & 0<\text { purchased quantity } \leqslant 1000 \\ \$ 2.92 & 1000<\text { purchased quantity } \leqslant 2000 \\ \$ 2.81 & 2000<\text { purchased quantity } \leqslant 3000 \\ \$ 2.76 & 3000<\text { purchased quantity }\end{cases}$

Unit price offered by supplier $B= \begin{cases}\$ 3.02 & 0<\text { purchased quantity } \leqslant 1199 \\ \$ 2.85 & 1199<\text { purchased quantity } \leqslant 2499 \\ \$ 2.79 & 2499<\text { purchased quantity } \leqslant 3999 \\ \$ 2.75 & 3999<\text { purchased quantity }\end{cases}$

Unit price offered by supplier $C= \begin{cases}\$ 3.06 & 0<\text { purchased quantity } \leqslant 800 \\ \$ 2.95 & 800<\text { purchased quantity } \leqslant 1600 \\ \$ 2.84 & 1600<\text { purchased quantity }\end{cases}$

Table 2

Values of $D_{\text {mnjs }}$ for supplier 1 of the numerical example of P1.

\begin{tabular}{|c|c|c|c|c|c|}
\hline & \multirow[t]{2}{*}{$m+1$} & \multicolumn{4}{|l|}{$\mathrm{n}$} \\
\hline & & 1 & 2 & 3 & 4 \\
\hline$D_{m n 11}$ & $\begin{array}{l}1 \\
2 \\
3 \\
4\end{array}$ & 900 & 2300 & 5000 & 7150 \\
\hline$D_{m n 21}$ & $\begin{array}{l}1 \\
2 \\
3 \\
4\end{array}$ & & $\begin{array}{l}2050 \\
1400\end{array}$ & $\begin{array}{l}4150 \\
3600\end{array}$ & $\begin{array}{l}5850 \\
5350\end{array}$ \\
\hline$D_{m n 31}$ & $\begin{array}{l}1 \\
2 \\
3 \\
4\end{array}$ & & & $\begin{array}{l}4400 \\
3800 \\
2800\end{array}$ & $\begin{array}{l}5950 \\
5400 \\
4450\end{array}$ \\
\hline$D_{m n 41}$ & $\begin{array}{l}1 \\
2 \\
3 \\
4\end{array}$ & & & & $\begin{array}{l}6250 \\
5600 \\
4450 \\
2150\end{array}$ \\
\hline
\end{tabular}

Table 3

Values of $D_{\text {mnjs }}$ for supplier 2 of the numerical example of P1.

\begin{tabular}{|c|c|c|c|c|c|}
\hline & \multirow[t]{2}{*}{$m+1$} & \multicolumn{4}{|l|}{$\mathrm{n}$} \\
\hline & & 1 & 2 & 3 & 4 \\
\hline$D_{m n 12}$ & $\begin{array}{l}1 \\
2 \\
3 \\
4\end{array}$ & 850 & 2350 & 5150 & 7200 \\
\hline$D_{m n 22}$ & $\begin{array}{l}1 \\
2 \\
3 \\
4\end{array}$ & & $\begin{array}{l}2600 \\
1900\end{array}$ & $\begin{array}{l}4800 \\
4200\end{array}$ & $\begin{array}{l}6400 \\
5950\end{array}$ \\
\hline$D_{m n 32}$ & $\begin{array}{l}1 \\
2 \\
3 \\
4\end{array}$ & & & $\begin{array}{l}4250 \\
3600 \\
2500\end{array}$ & $\begin{array}{l}5700 \\
5200 \\
4300\end{array}$ \\
\hline$D_{m n 42}$ & $\begin{array}{l}1 \\
2 \\
3 \\
4\end{array}$ & & & & $\begin{array}{l}6300 \\
5700 \\
4600 \\
2200\end{array}$ \\
\hline
\end{tabular}

Table 4

Values of $F_{m}+D_{m n j s}$ for supplier 1 of the numerical example of P1.

\begin{tabular}{|c|c|c|c|c|c|}
\hline & \multirow[t]{2}{*}{$m+1$} & \multicolumn{4}{|l|}{$\underline{\mathrm{n}}$} \\
\hline & & 1 & 2 & 3 & 4 \\
\hline$F_{m}+D_{m n 11}$ & $\begin{array}{l}1 \\
2 \\
3 \\
4\end{array}$ & 900 & 2300 & 5000 & 7150 \\
\hline$F_{m}+D_{m n 21}$ & $\begin{array}{l}1 \\
2 \\
3 \\
4\end{array}$ & & $\begin{array}{l}2050 \\
2250\end{array}$ & $\begin{array}{l}4150 \\
4450\end{array}$ & $\begin{array}{l}5850 \\
6200\end{array}$ \\
\hline$F_{m}+D_{m n 31}$ & $\begin{array}{l}1 \\
2 \\
3 \\
4\end{array}$ & & & $\begin{array}{l}4400 \\
4650 \\
4850\end{array}$ & $\begin{array}{l}5950 \\
6250 \\
6500\end{array}$ \\
\hline$F_{m}+D_{m n 41}$ & $\begin{array}{l}1 \\
2 \\
3 \\
4\end{array}$ & & & & $\begin{array}{l}6250 \\
6450 \\
6500 \\
6300\end{array}$ \\
\hline
\end{tabular}

Table 5

Values of $F_{m}+D_{m n j s}$ for supplier 2 of the numerical example of P1.

\begin{tabular}{|c|c|c|c|c|c|}
\hline & \multirow[t]{2}{*}{$m+1$} & \multicolumn{4}{|l|}{$\mathrm{n}$} \\
\hline & & 1 & 2 & 3 & 4 \\
\hline$F_{m}+D_{m n 12}$ & $\begin{array}{l}1 \\
2 \\
3 \\
4\end{array}$ & 850 & 2350 & 5150 & 7200 \\
\hline$F_{m}+D_{m n 22}$ & $\begin{array}{l}1 \\
2 \\
3 \\
4\end{array}$ & & $\begin{array}{l}2600 \\
2750\end{array}$ & $\begin{array}{l}4800 \\
5050\end{array}$ & $\begin{array}{l}6400 \\
6800\end{array}$ \\
\hline$F_{m}+D_{m n 32}$ & $\begin{array}{l}1 \\
2 \\
3 \\
4\end{array}$ & & & $\begin{array}{l}4250 \\
4450 \\
4550\end{array}$ & $\begin{array}{l}5700 \\
6050 \\
6350\end{array}$ \\
\hline$F_{m}+D_{m n 42}$ & $\begin{array}{l}1 \\
2 \\
3 \\
4\end{array}$ & & & & $\begin{array}{l}6300 \\
6550 \\
6650 \\
6350\end{array}$ \\
\hline
\end{tabular}


Table 6

Data entry for the numerical example of P2.

$\begin{array}{lllllllllllll}\boldsymbol{t} & 1 & 2 & 3 & 4 & 5 & 6 & 7 & 8 & 9 & 10 & 11 & 12\end{array}$

$\begin{array}{lllllllllllll}\boldsymbol{d}_{\boldsymbol{t}} & 650 & 710 & 550 & 100 & 660 & 530 & 500 & 440 & 350 & 240 & 780 & 810\end{array}$

demands and minimize the total cost. We study two different situations of a planning horizon with 7 or 12 periods.

In the first case, we examine a planning horizon of 7 periods (from period 1 to 7 ). Solving the corresponding MILP via Gurobi 6.5.2, gives an optimal total cost of $\$ 11,172$ where 2010 and 1690 units of ITO films are to be purchased in periods 1 and 5, respectively, from supplier C. EIFDP also reaches the same optimal solution. Both MILP and EIFDP find the optimal objective in less than a second. If the manufacturer implements a single supplier policy and purchases all the requirements from supplier $\mathrm{A}$, then the optimal total cost will be $\$ 11406.9$ which is $2.1 \%$ higher than that of the multiple supplier strategy described above.

In the second case, we examine a planning horizon with 12 periods. By solving this problem using the MILP model, we obtain an optimal policy of buying 2010 units in period 1 from supplier C, 2500 units in period 5 from supplier B, and 1810 units in period 10 from supplier C, with an optimal total cost of $\$ 19209.8$. However, the EIFDP model reaches a different solution with a total cost of $\$ 19215.7$ which has a $0.03 \%$ error from the optimal objective value acquired by the MILP model. MILP and EIFDP reach an optimal and a near-optimal solution, respectively, in less than a second. If the manufacturer continues to cooperate only with supplier A, then the optimal total cost will be $\$ 19368.2$ which is $0.82 \%$ greater than that of the multiple supplier policy.

Examining the two cases above for P2 demonstrates that implementing a multiple supplier strategy is more profitable than a single supplier one. Moreover, in view of the fact that the MILP model solves these problems optimally, whereas, the EIFDP model does not guarantee an optimal solution, and both models reach the solution quite quickly, we can infer that for such small sized problems implementing the MILP model is more worthwhile than EIFDP. However, as shown in the next section, for the multiple supplier case, MILP is not able to solve moderate or large sized problems within a time limit of 1800 seconds.

\section{Computational results}

In order to examine the efficiency of the presented recursive formulations, forward dynamic programming (FDP) algorithms are obtained from each set of Eqs. (7) and (8) for P1, and, (7) and (22) for P2. Moreover, Eqs. (7) and (9) for P1, and, (7) and (23) for P2, result in the efficient implementations of forward dynamic programming (EIFDP) algorithms. These algorithms are coded by C\# programming language and run via a personal computer (ASUS X450C Laptop, 6 GB RAM, Intel core i5 processor $1.8 \mathrm{GHz}$, Windows 8). The MILP models are also solved using Gurobi 6.5.2 on the same computer. 5 random instances are generated for each problem size consist of $T$ periods and $S$ suppliers using the following intervals and with the uniform distribution. We use a time limit of $1800 \mathrm{~s}$.

$$
\begin{aligned}
& d_{t} \in \operatorname{int}[50,300] \\
& C_{s t} \in \operatorname{int}[600,1000] \\
& U_{1 s t} \in \operatorname{int}[14,16] \\
& U_{2 s t} \in \operatorname{int}[11,13] \\
& U_{3 s t} \in \operatorname{int}[8,10] \\
& Q_{1 s t} \in \operatorname{int}[300,400] \\
& Q_{2 s t} \in \operatorname{int}[600,700] \\
& h_{t}^{+} \in \operatorname{int}[1,4] \\
& h_{t}^{-} \in \operatorname{int}[1,4]
\end{aligned}
$$

Table 7

Computational results of optimal solutions for P1.

\begin{tabular}{lllll}
\hline \multirow{2}{*}{ Num. of periods } & $\begin{array}{l}\text { Num. of } \\
\text { suppliers }\end{array}$ & FDP for P1 & EIFDP for P1 & MILP for P1 \\
\hline 50 & 1 & $0.07(5)$ & $0.01(5)$ & $44.12(5)$ \\
& 5 & $0.32(5)$ & $0.05(5)$ & - \\
& 25 & $1.63(5)$ & $0.34(5)$ & - \\
& 50 & $3.29(5)$ & $0.62(5)$ & - \\
100 & 1 & $1.77(5)$ & $0.12(5)$ & - \\
& 5 & $8.75(5)$ & $0.60(5)$ & - \\
& 25 & $44.07(5)$ & $3.23(5)$ & - \\
& 50 & $87.11(5)$ & $6.44(5)$ & - \\
150 & 1 & $12.77(5)$ & $0.49(5)$ & - \\
& 5 & $62.58(5)$ & $2.40(5)$ & - \\
& 25 & $316.98(5)$ & $12.74(5)$ & - \\
& 50 & $631.52(5)$ & $25.65(5)$ & - \\
\hline
\end{tabular}

Table 8

Computational results of heuristics and MILP (optimal solution) for P2.

\begin{tabular}{lllllll}
\hline $\begin{array}{l}\text { Num. of } \\
\text { periods }\end{array}$ & $\begin{array}{l}\text { Num. of } \\
\text { suppliers }\end{array}$ & $\begin{array}{l}\text { FDP for } \\
50\end{array}$ & $\begin{array}{l}\text { EIFDP } \\
\text { for P2 }\end{array}$ & $\begin{array}{l}\text { MILP } \\
\text { for P2 }\end{array}$ & $\begin{array}{l}\text { Average } \\
\text { gap }\end{array}$ & $\begin{array}{l}\text { Maximum } \\
\text { gap }\end{array}$ \\
\hline & 5 & $0.06(5)$ & $0.01(5)$ & $0.38(5)$ & $0.80 \%$ & $1.47 \%$ \\
& 25 & $0.30(5)$ & $0.04(5)$ & $9.20(5)$ & $1.15 \%$ & $2.59 \%$ \\
& 50 & $1.56(5)$ & $0.24(5)$ & $109.46(3)$ & $1.46 \%$ & $2.15 \%$ \\
100 & 1 & $1.17(5)$ & $0.49(5)$ & - & - & - \\
& 5 & $8.68(5)$ & $0.50(5)$ & $97.39(5)$ & $1.04 \%$ & $1.15 \%$ \\
& 25 & $44.81(5)$ & $2.77(5)$ & - & - & - \\
& 50 & $86.36(5)$ & $5.48(5)$ & - & - & - \\
150 & 1 & $12.55(5)$ & $0.43(5)$ & $5.74(5)$ & $1.08 \%$ & $1.40 \%$ \\
& 5 & $62.21(5)$ & $2.08(5)$ & $184.04(5)$ & $0.94 \%$ & $1.42 \%$ \\
& 25 & $313.65(5)$ & $11.1(5)$ & - & - & - \\
& 50 & $626.18(5)$ & $22.26(5)$ & - & - & - \\
\hline
\end{tabular}

For each problem size, the average time (in seconds) of random instances that are solved within the time limit, is demonstrated in the following Tables 7 and 8 . The number of solved instances are given in the parenthesis. For P2, the average optimality gap between the optimal solution obtained by MILP and the heuristic solution obtained by FDP and EIFDP, is also presented along with the maximum optimality gap. The optimality gaps are reported only for instances that MILP model could reach their optimal solutions within the time limit. The optimality gaps are calculated using this formula: $\frac{\text { heuristic objective value-optimal objective value }}{\text { optimal objective value }}$

\subsection{Discussion}

Computational results demonstrate that MILP for incremental discount case is inefficient as in our settings it can only solve small sized instances (only one supplier and 50 periods) within the time limit. However, both FDP and EIFDP give the optimal solution even for large sized instances within the same time limit where EIFDP is averagely 15 times faster than FDP, for P1. Therefore, we can conclude that among the models studied in this paper, EIFDP is the best option for solving the DLSP with multiple suppliers, backlogging and incremental quantity discount.

In the presence of all-units quantity discounts, MILP solves all the instances optimally within the time limit for the single supplier case, even when the number of periods is large. Although, EIFDP is quite faster than MILP, it does not guarantee an optimal solution. For the multiple supplier case, MILP still solves small sized instances optimally within the time limit, however, it fails to solve moderate or large sized problems. For all the examined instances for P2, including the large sized ones, EIFDP reaches the same near optimal solution (with less than $1.1 \%$ optimality gap on average 
and $2.59 \%$ optimality gap in the worst case) as FDP very quickly and in average 17 times faster than FDP. Hence, we can infer that, when suppliers offer all-units quantity discounts, if a good solution is needed timely especially for large sized problems, one should use EIFDP model. Otherwise, if having the optimal solution is vital for the buyer or the problem size is small, MILP model is advised for solving the problem.

\section{Conclusions}

The single product dynamic lot sizing problem with supplier selection and backlogging is discussed in this paper in the presence of incremental and all-units quantity discounts which results in two different cases. One of the most important applications of the proposed model is when the shortage in the system is allowed. New mixed integer linear programming (MILP) models are established for each case. Moreover, a recursive formulation and its efficient implementation is developed yielding an optimal solution for the incremental discount case, and a near optimal solution for allunits discount case. For each case, we solve the MILP model using a commercial software and run a dynamic programming model (FDP) obtained from recursive formulation and its efficient implementation (EIFDP). We then provide the corresponding computational studies of the proposed models the results of which demonstrate that when all suppliers offer incremental quantity discounts for purchasing an item, MILP model is quite time consuming even for small sized instances while the EIFDP model gives the optimal solution very quickly even for large sized instances. For all-units quantity discount cases, MILP model can only solve small sized instances in a reasonable time whereas EIFDP obtains a near optimal solution (less than $1.1 \%$ optimality gap on average) quite timely even for large sized instances. The computational results also show that EIFDP performs much faster than FDP.

For future research, the authors recommend the extension of the problems introduced in this article, to the multiple product case. Moreover, this research may be extended further by considering the proposed model in uncertain environments with stochastic demand or fluctuation in price.

\section{References}

Absi, N., Kedad-Sidhoum, S., \& Dauzère-Pérès, S. (2011). Uncapacitated lot-sizing problem with production time windows, early productions, backlogs and lost sales. International Journal of Production Research, 49(9), 2551-2566.

Aggarwal, A., \& Park, J. K. (1993). Improved algorithms for economic lot-size problems. Operations Research, 41(3), 549-571.

Bai, Q.-G., \& Xu, J.-T. (2011). Optimal solutions for the economic lot-sizing problem with multiple suppliers and cost structures. Journal of Applied Mathematics and Computing, 37(1-2), 331-345.

Burke, G. J., Erenguc, S. S., \& Vakharia, A. J. (2008). Optimal requirement allocation among quantity-discount quoting suppliers. Operations Management Research, 1 (1), 53-60.

Callerman, T. E., \& Whybark, D. C. (1977). Purchase quantity discounts in an MRP environment. In 8 th annual midwest conference. .

Chang, C.-T. (2006). An acquisition policy for a single item multi-supplier system with real-world constraints. Applied Mathematical Modelling, 30(1), 1-9.

Chang, C.-T., Chin, C.-L., \& Lin, M.-F. (2006). On the single item multi-supplier system with variable lead-time, quantity discount, and resource constraints, Applied Mathematics and Computation, 182(1), 89-97.
Chaudhry, S. S., Forst, F. G., \& Zydiak, J. L. (1993). Vendor selection with price breaks. European Journal of Operational Research, 70(1), 52-66.

Chu, C., Chu, F., Zhong, J., \& Yang, S. (2013). A polynomial algorithm for a lot-sizing problem with backlogging, outsourcing and limited inventory. Computers $\mathcal{E}$ Industrial Engineering, 64(1), 200-210.

Chung, C. S., Chiang, D. T., \& Lu, C. Y. (1987). An optimal algorithm for the quantity discount problem. Journal of Operations Management, 7(1), 165-177.

Chyr, F., Huang, S.-T., \& Lai, S. D. (1999). A dynamic lot-sizing model with quantity discount. Production Planning \& Control, 10(1), 67-75.

Dai, T., \& Qi, X. (2007). An acquisition policy for a multi-supplier system with a finite-time horizon. Computers \& Operations Research, 34(9), 2758-2773.

Evans, J. R. (1985). An efficient implementation of the Wagner-Whitin algorithm for dynamic lot-sizing problem. Journal of Operational Management, 5(2), 229-235.

Federgruen, A., \& Lee, C.-Y. (1990). The dynamic lot size model with quantity discount. Naval Research Logistics, 37(5), 707-713.

Federgruen, A., \& Tzur, M. (1991). A simple forward algorithm to solve general dynamic lot-sizing models with $n$ periods in $\mathrm{O}(\mathrm{n} \log \mathrm{n})$ or $\mathrm{O}(\mathrm{n})$ time. Management Science, 37(8), 909-925.

Fordyce, J. M., \& Webster, F. M. (1985). Nonconstant unit cost/price with the Wagner-Whitin algorithm. Production and Inventory Management, 26(1), 71-80.

Hu, J., \& Munson, C. L. (2002). Dynamic demand lot-sizing rules for incremental quantity discounts. Journal of the Operational Research Society, 53(8), 855-863.

Jaruphongsa, W., Cetinkaya, S., \& Lee, C. Y. (2005). A dynamic lot-sizing model with multi-mode replenishments: Polynomial algorithms for special cases with dual and multiple modes. IIE Transactions, 37(5), 453-467.

Kang, H. Y., \& Lee, A. H. (2013). A stochastic lot-sizing model with multi-supplier and quantity discounts. International Journal of Production Research, 51(1), 245-263.

Lee, A. H., Kang, H. Y., \& Lai, C. M. (2013). Solving lot-sizing problem with quantity discount and transportation cost. International Journal of Systems Science, 44(4), 760-774.

Lee, A. H., Kang, H. Y., Lai, C. M., \& Hong, W. Y. (2013). An integrated model for lot sizing with supplier selection and quantity discounts. Applied Mathematical Modelling, 37(7), 4733-4746.

Mazdeh, M. M., Emadikhiav, M., \& Parsa, I. (2015). A heuristic to solve the dynamic lot sizing problem with supplier selection and quantity discounts. Computers $\mathcal{E}$ Industrial Engineering, 85, 33-43.

Parsa, I., Khiav, M., Mazdeh, M., \& Mehrani, S. (2013). A multi supplier lot sizing strategy using dynamic programming. International Journal of Industria Engineering Computations, 4(1), 61-70.

Roodhooft, F., \& Konings, J. (1996). Vendor selection and evaluation an activity based costing approach. European Journal of Operational Research, 96(1), 97-102.

Rosenblatt, M. J., Herer, Y. T., \& Hefter, I. (1998). Note. An acquisition policy for a single item multi-supplier system. Management Science, 44(11), S96-S100.

Song, Y., \& Chan, G. H. (2005). Single item lot-sizing problems with backlogging on a single machine at a finite production rate. European Journal of Operationa Research, 161(1), 191-202.

Stadtler, H. (2007). A general quantity discount and supplier selection mixed integer programming model. OR Spectrum, 29(4), 723-744.

Sumichrast, R. T. (1986). Lot sizing through the Fordyce-Webster heuristic. Production and Inventory Management Journal, 27(4), 102-109.

Tempelmeier, H. (2002). A simple heuristic for dynamic order sizing and supplier selection with time-varying data. Production and Operations Management, 11(4) 499-515.

Van Hoesel, S., Kuik, R., Salomon, M., \& Van Wassenhove, L. N. (1994). The singleitem discrete lot sizing and scheduling problem: Optimization by linear and dynamic programming. Discrete Mathematics, 48(3), 289-303.

Wagelmans, A., Van Hoesel, S., \& Kolen, A. (1992). Economic lot sizing: An O(n log n) algorithm that runs in linear time in the Wagner-Whitin case. Operations Research, 40(1), S145-S156.

Wagner, H. M., \& Whitin, T. M. (1958). Dynamic version of the economic lot size model. Management Science, 5(1), 89-96.

Xu, J., \& Lu, L. L. (1998). The dynamic lot size model with quantity discount: Counterexamples and correction. Naval Research Logistics, 45(4), 419-422.

Zangwill, W. I. (1966). A deterministic multi-period production scheduling model with backlogging. Management Science, 13(1), 105-119.

Zangwill, W. I. (1969). A backlogging model and a multi-echelon model of a dynamic economic lot size production system - A network approach. Management Science, 15(9), 506-527.

Zhao, Y., \& Klabjan, D. (2012). A polyhedral study of lot-sizing with supplier selection. Discrete Optimization, 9(2), 65-76. 